\title{
Kurjad keeled sugupooli käsitlevates naljades
}

Sabine Wienker-Piepho

Näib, et uusimais sugupoolte uuringuis ei saada adjektiivita «pahatahtlik» enam kuidagi hakkama. Raamatut pealkirjaga «Head tüdrukud lähevad taevasse, pahad igale poole - miks ei vii pai-olemine meid edasi» $*_{1}$ on müüdud üle miljoni eksemplari. Kas tuntud sõna «paha, kuri» on saanud selle käigus moesõnaks või on see lihtsalt uuem opositsioon sõnale «pai-olemine», mis on omandanud tähendusvarjundi «kahjutuna, ohutuna paista laskmine»? Ehk on ajastul, millele on omased vägivallapursked ja üha brutaalsemaks muutuv võitlus töökohtade pärast, tekkinud uus «pahatahtlikkuse argipäev» sugupoolte vahel? $*_{2}^{2}$ Kui see nii oleks - nagu kogemus näitab ja iga jutu-uurija teab -, siis peaks see nn pahatahtlikkus olema ka igapäevases jutustamises märgatav, näiteks naljade juures, kuna just neid kasutatakse tihti tõhusa relvana. Tegelikkuses tundub see just nii olevat. Naljadesse kätketud vastastikune löögivalmidus on jõudnud uutesse dimensioonidesse. «Torkavad» eelkõige meeste teravused.

Tähelepanelikud vaatlejad konstateerivad aga ka naissoost sõnaseppade olemasolu, kes muutuvad senitundmatul moel aina kurjemaks. Kena suhtumine ja tänulik tolerantsus nõrkade meeste suhtes näib olevat möödas: naiste seltskondades sööklas, kohvilauas, töö juures, trammis, ujulas ja saunas on pehme iroonia taandunud otsesõnalise alatuse ees. Mehed seevastu suunavad vanemast ajast ülekandunud naljad uue teravusega naiste poole. Naljad vastassoo kohta, olgu need siis mehi või naisi alavääristavad, näivad kuuluvat hea tooni juurde ning just naljakana mõeldud puändis näib agressiivne pahatahtlikkus olevat moeprintsiibiks. Naljavormis verbaalne rünnak on nii äge, nagu poleks poliitilist korrektsust ja seksuaalset ahistamist puudutavaid debatte varem kunagi olnud, ning tagasilöök käib samade relvadega, nimelt sarnaste naljade abil.

Teadlaste jaoks on naljad ühiskonna seisundi signaalideks ja tõestusmaterjaliks. Freiburgi naljauurija Lutz Röhrich esindab arusaama, mille kohaselt naljad on «antud inimgrupi psühhogrammi indikaatorid» (Röhrich 1990: 132). Ka André Jolles, üks folkloristika isasid, arvas juba kolmekümnendatel aastatel oma tuntud teoses Einfache Formen: «Rahvanali tähistab oma laadi, naljatamisviisi kaudu ... konkreetset rahvast, gruppi, aega, millest ta on võrsunud» (Jolles 1958: 247). Naljauurimine on alati olnud mosaiigikiviks üldisemas ühiskonnaanalüüsis.

Seni pole ühelgi üldises naljadebatis osaleval teadusharul õnnestunud pakkuda usaldusväärseid andmeid naljade leviku, erinevate kihistuste spetsiifika, retseptsiooni ja funktsiooni kohta. See puudujääk on omane eelkõige siinkäsitletud naljade alaliigile, sealhulgas nendele, mis seostuvad mõistega gender, sotsiaalne sugupool. *3 Kas on needki seotud teatava intellektuaalse või sotsiaalse miljööga? On neile ehk omane teatav interaktiivne esitusvorm, mille poolest need erinevad ülejäänutest? Ja lõpuks: kui agressiivsed on sugupoolte naljad üleüldse? Veelkord peab esitama ka kultuuriga seotuse küsimuse, s.t kas võivad need naljad oma põhisisu muutmata liikuda üle kultuuripiiride? Või et küsimust täpsustada: kas need suudavad püsida kultuurides, milles valitseb sugude vahel printsipiaalselt teistsugune suhtumine? Kas leiduks muudes maades üldse selliste naljade üle naerjaid või jääks see fenomen kuulajatele täiesti mõistmatuks. 


\section{Kontekstid}

Avalikud küsitlused on tihti keeruliste rõhuasetustega. Õigupoolest märkab inimene, kes pilgu tänapäeva naljamaastikule heidab, peagi, et vaatamata trükitud naljakogumikele jäävad suuliselt leviva traditsiooni kontekstid endiselt haaramatuks. Olgugi et Karin Huffzky avaldas juba 1979 materjalirohke kogumiku naise kujutamisest meestenaljades (Huffzky 1979), olgugi et hiljuti ilmus naisi halvustavate naljade loome ja retseptsiooni kohta artiklikogumik «Sugupoolte kohta käivad naljad» (Gelächter der Geschlechter), mis käsitleb neid meediateaduse küljelt, on kontekst - eriti mis puudutab vanemaid, pikaealisemaid naistevastaseid nalju - jäetud tähelepanuta. Ka Lutz Röhrichi naljaraamat, mis ilmus esmakordselt 1977 (Röhrich 1977) ja mida võib siiani klassikaliseks teoseks pidada, ei ütle konteksti kohta peaaegu midagi, sama puudus on tema juhendamisel loodud Freiburgi rahvaluuleinstituudi naljaarhiivil, kust pärineb ka muist järgnevalt esitatud näidetest. $\stackrel{* 4}{ } \mathrm{Ka}$ üldine sotsiaalne naisuuring on jututraditsioonist nii suure kaarega mööda läinud, et naljauurimise feminiseerumisest ei saa juttugi olla. $*_{5}^{5}$ Konkreetselt sooerinevustest tingitud jutustamiskontekstide kohta pole siiani seisukohta võetud, olgugi et see oleks pidanud kuuluma näiteks Göttingeni jutu-uurija Elfriede Moser-Rathi 1978. aastal avaldatud esimese uurimuse juurde. Alles siis, kui nn blondiininaljad umbes viie aasta eest moodi tulid, elustus vaidlus uuesti.

Blondiininaljad propageerivad silmanähtavalt naiste ületamatut rumalust, nagu oleks tarkus vaid meeste kaasasündinud privileeg. See klishee asetub vanemate - jonnaka, pudrunuiaga relvastatud abikaasa, kurja ämma ja peaaegu nõdrameelse Tiiu-talutütrekese, madala IQ tasemega sekspommi ja nümfomaanse sekretäri stereotüüpide kõrvale. Hermann Bausinger kirjutas 1995 artikli, milles ta üritas paljastada blondiininaljade traditsioonilisust ja nende võimalikku kontinuiteeti. Tema arvates meenutavad blondiininaljade blondiinid vanemaid naljategelasi (Bausinger 1995: 17 jj.). Selles mõttes võiks madala intelligentsi rõhutamine blondiininaljades olla üle võetud vanematest idiootide või idafriislaste kohta käivatest naljadest, ohjeldamatu seksikire osas seevastu oleksid eeskujudeks vananenud nn Nitribitt-naljad ja rumaluse osas Manta-juhtide sõbrannade (enamasti juuksurite) naljad. Heledapäisus ise jäi kultuuriajalooliselt mõistatuslikuks: ka Bausingeril ei õnnestunud seda ajalooliselt mingi paikkonnaga seostada või isegi - vähemalt pole ta seda katsetanud - leida jälgi blondiininaljadest kultuurides, kus elavad ainult mustajuukselised või domineerivad blondid. $\underline{* 6}$

Moser-Rath jõudis oma ülalmainitud uurimuses aastasadade vanuseid naistevastastes naljades esinevaid konstante vaadeldes oletuseni, et peale naljade on ehk teisigi võimalusi diskrimineerimise väljendamiseks. Kui uskuda aga õpilaste, õpetajate ja tudengite teateid, on just nimelt blondiininaljad ekstreemselt haavavad. Lõppude lõpuks võib - nagu igaüks teab - just puberteedieas sugudevaheline võitlus jõuda väljakannatamatult agressiivsete vormideni. Alates sellest, kui Saksamaal blondiininaljad levivad, on blonde tüdrukuid nende juuksevärvi pärast pidevalt narritatud. Vastavalt mõnedele teadetele ei aidanud ka see, kui vaesed lapsed oma juuksed roheliseks või siniseks värvisid. $* 7$

\section{Vahendajad}

Tänapäeval määrab uuema saksa argikultuuri jutustamispaigad televisioon. Viimasel ajal propageeritakse Saksa televisioonis huumorit populaarsete «naljajutustamise võistluste» kaudu, mis on tegelikult Ameerika kultuuriimport.

Selle kõrval aitab aga ikka veel trükimeedia kaasa naljade populariseerimisel ja seega ka sugupoolte kohta käivate klisheede kujunemisel. Nagu varemgi võib kioskitest, kaubahallidest, raamatu- ja 
kirjatarvete kauplustest osta naljakogumikke (vrd Schenda 1978). Need vihikukesed on tihti üllatavalt vanamoodsad, kuna nii neis kui ka ajakirjade naljalehekülgedel domineerivad endiselt «sekspommid». Selle militaarse värvinguga väljendi abil märgistab saksa keel napilt riietatud naistüüpi, kellel on ülidimensioonides ülakeha, sama võimsalt väljajoonistunud puusad ja tobe-meelas näoilme, mis kuritarvitab rafineeritult meeste seksuaaltunge, et oma sotsiaalset olukorda parandada. Lihtsaid pakkumise ja nõudmise seadusi arvestades peab rahval olema ikka veel vajadus selliste naljaobjektide või üldse trükitud naljakogumike järele, muidu poleks neid võimalik produtseerida ja müüa. Trükitud meediumidest vahendavad arvukalt naistevaenulikke nalju nn meesteajakirjad. Rootsi folklorist Ulf Palmenfeld võrdles ja hindas 1990. aastal kokku nelja ajakirja kümnest aastakäigust pärit 2000 nalja. Tema uurimuse pealkirjaks on Stereotypical Characters in Erotic Jokes (Palmenfeld 1990). Väidetavalt on suurim osa neis ajakirjades publitseeritud naljadest valdavalt meeslugejate poolt toimetusele saadetud, mõnel juhul on tegemist naljavõistlusega, mis peaks seda tegevust ergutama.

\section{Tekstid ja suulisuse probleem}

Kindlasti ei piisa ainult levikuteede väljaselgitamisest, kuigi suulisus otsesemalt või kirjalikkus distantseeritumalt, kuid siduvamalt näib olevat verbaalse tülikultuuri kurjuse astmega seotud. Nii tõusevad ka moodsas meedias viimasel ajal esile rohkem või vähem pahatahtlikud ühe ja sama suunitlusega nilbed süzheed. Tihti, kuigi trükitud vormis harvemini, jõuavad nimelt sugude kohta käivad naljad naistevihkajalike, pornograafiliste seksismide tasemele, mis - nagu järgmiseski naljas - käivad mehe suguorgani asendatavuse kohta:

Kas te teate, mis oli naistevangla revolutsiooni põhjus? - Sest uuemal ajal lõigatakse porgandid tükkideks, selle asemel, et neid tervelt serveerida nagu varem.

Seegi nilbus kuulub meestejuttude (male tales) hulka, kuna need silmanähtavalt pakuvad huvi ainult meestele. Väidetavalt räägitakse neid väga harva naiste seltskonnas. Sellest faktist nähtuva soospetsiifilise funktsiooni üle on samuti palju juureldud $\underline{* 8}$ edasiviivate järeldusteni jõudmata. Diskussioonid ei toimu ainult feministide ringkonnas. Ka Freud, kes arutledes oma kuulsas raamatus Nali ja selle seos alateadvusega (esmakordselt 1905) meeste poolt räägitavate nilbuste mehhanismide üle, näitas ühes teravmeelses tõenduses, kuidas naine degradeeritakse kõige vaenulikumate agressioonide objektiks (Freud 1989: 78), naine ise aga ennast seeläbi ei degradeeri. Samas ei aidanud nilbuste vastu võitlejaid ei need teadmised ega 90. aastate nn «PorNo»-kampaaniad; nilbused elasid enneolematu jõuga edasi. $\stackrel{* 9}{ }$

Pornograafilistest nilbustest pole kaugel needki naljad, milles pakutakse vägivalda naiste vastu ning meeliskletakse häbenematult ka mõrvateemadel:

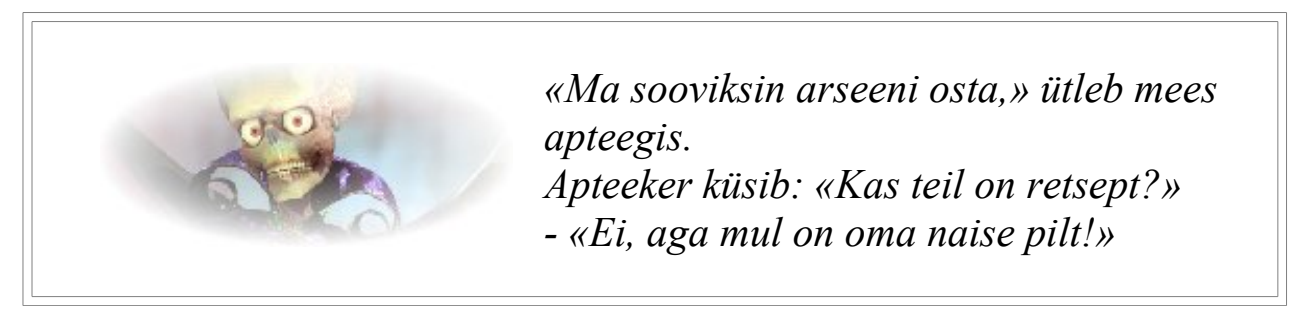


Siinsel napi vormelini lühendatud brutaalsel vastumeelsest naisest vabanemise moodusel on kauaaegne traditsioon: «Peksa oma naist iga päev, kui sa ei tea, millepärast - siis küll tema teab», pärineb 17. sajandist ning sada aastat enne seda öeldi Prantsusmaal: «Löö oma naist, nagu sa nisu peksad, siis saab sul hea vili ja ilusad lapsed olema.» Sellised küünilised pahatahtlikkused kohandatakse sadadeks vägistaja-naljadeks, zhanriks, mis naiste kontekstis peaaegu puudub:

Noor tütarlaps jookseb politseisse ja karjub: »Aidake mind, palun, üks nõdrameelne vägistas mu pargis ära.» - «Ma saan teie erutusest aru,» ütleb ametnik, "aga kust te teate, et see nõdrameelne oli?» - «Sellest, et ma pidin talle isegi seda näitama, kuidas see käib.»

Teised meestenaljad võtavad targa naise luubi alla ja ka see suund baseerub aastasadade - vanustel eelarvamustel («Pikad juuksed, lühike aru», «Ladina keelt oskav naine jäta rahule» jne). Sellega sarnaselt on põlatud naisõiguslased saanud tänuväärseks naljaobjektiks, eriti kui nad väidetavatel meeste aladel, nagu ülikool ja parlament, esile kerkivad. Nii esitavad meeste naljad Saksa valitsuses enamasti «subtiilseid väljalülitusmehhanisme» naiste arvel (vrd Kotthoff 1996: 35):

Kas te teate absoluutselt kõige tõhusamat homoöpaatilist ravivahendit Kreuthist? - See on Kreutheri tee. Selle tee abil pikendati Annemarie Rengeri legislatuuriperioodi nelja aasta võrra.

Tihti baseerub naistevaenulik nali võrdlusel loomadega, kui jätta tähelepanuta tõsiasi, et naisi, kes ei suuda selliste naljade peale naerda, kiputakse kohe pirtsakaks [«zickig» - tõlgitav ka kui 'kitselik'] nimetama:

Mis vahe on abielunaisel ja töölkäival naisel? - Abielunaine on kui töötu suguloom ja töölkäija on kui sootu tööloom.

Mida seksistlikum ja agressiivsem on nali, seda rohkem kaldub ta suulisele levimisele. Näib, nagu oleks vahendajatel siiski mingi hirm selle ees, mis must-valgel ära trükitakse. Nii Röhrich kui Schenda, kelle rahvaliku jutustamise ajalugu riivab naljateemat küll vaid nurkapidi, rõhutavad, et suulised naljad ja seksiteema leiavad käsitlust peamiselt meeste kõrtsiringkondades ja domineerivad seal kõikide teiste jutustamisliikide üle (Röhrich 1990, Schenda 1993: 263). Kuid ainuüksi lokaliseerimise ja sagedusanalüüsiga ei ole suulisuse versus kirjalikkuse probleem nalja juures veel ammendatud, sest vastastikuse mõjustatuse kohta ei anna selline käsitlus veel mingit olulist informatsiooni. Nagu kõigi suuliste esituste juures on ka praegusel juhul mõeldav, et mõned neist torkivatest naljamatadooridest on oma naljad kusagilt lugenud. 
Mis puutub jutustamise funktsiooni, siis tekib mulje, et naistevaenulikest naljadest - eriti neist, millel on ajalooline tagapõhi - aimub teatav hirm «teistsugususe», naiselikkuse ees, mida sel kombel lihtsamatesse, teadaolevatesse seletuskategooriatesse püütakse kanaliseerida. Naljade rääkimine funktsioneerib sel juhul hirmu peletamise mehhanismina traditsiooniliseks kinnistunud meetodite abil.

\section{Naised annavad vastulöögi}

Kõike seda teades pole ime, et naised on hakanud end viimasel ajal sellise agressiivse naeruvääristamise vastu kaitsma. Seda verbaalset vasturünnakut on mõjutanud ka praegune olukord ühiskonnas. Üks tõend üldisest üleminekust naistevaenulikkuselt meeste vastu suunatud huumorile on nähtav ka selles, et lõpuks on areenile hakanud tulema ka naiskarikaturistid, kabaretistid, klounid ja satiirikud, et viimasedki meeste valdkondadeks peetavad alad vallutada. Isegi väidetavalt huumorivaesel Saksamaal (vrd Betz 1993) on koomikuloomuga naised endale selles vallas juba nime teinud. Kahjuks on käesolevas artiklis ruumipuudusel võimalik vaid viitamisi näidata, milliseid vahendeid naised oma naljades kasutavad. Tuntuim nali, mida räägivad naised naistele ja mis käib meeste kohta ,on õigupoolest kõnekäänd. See on 1980-ndate alguses üle kandunud Ameerikast: Naine meheta on kui kala jalgrattata (vrd Mieder 1982). Mitmed järgnevad naljad opereerivad sama printsiibiga, nimelt ideega, et mehed on õigupoolest täiesti üleliigsed või kõlbavad vaid tööjõuks või hõlpsalt asendatavateks voodikaaslasteks. Seejuures läheneb kuri naisekeel siin kohati juba nilbusele nagu järgmiseski naljas, mis pärineb üldiselt korralikust naisteajakirjast Brigitte:

Miks lõi jumal mehe? - Sest vibraatoriga ei saa muru pügada.

Ning naisteajakirjast $E M M A$ võib lugeda:

Tema: «Miks ei ütle sa mulle iialgi, kui sa orgasmi saad?»

- Temake: «Sellepärast, et sind pole kunagi sel ajal läheduses olnud.»

Naiste nilbused pole kindlasti vähem diskrimineerivad ja agressiivsed kui meeste omad - naiste nilbus (nagu üldse meestevastased naljad) on aga vaid vastulöök, vaid selleks, et naistevaenulikku nalja kui sellist paljastada. Ümberpööratud vastulöök on kõige paremini demonstreeritav blondiininaljade kaudu: 


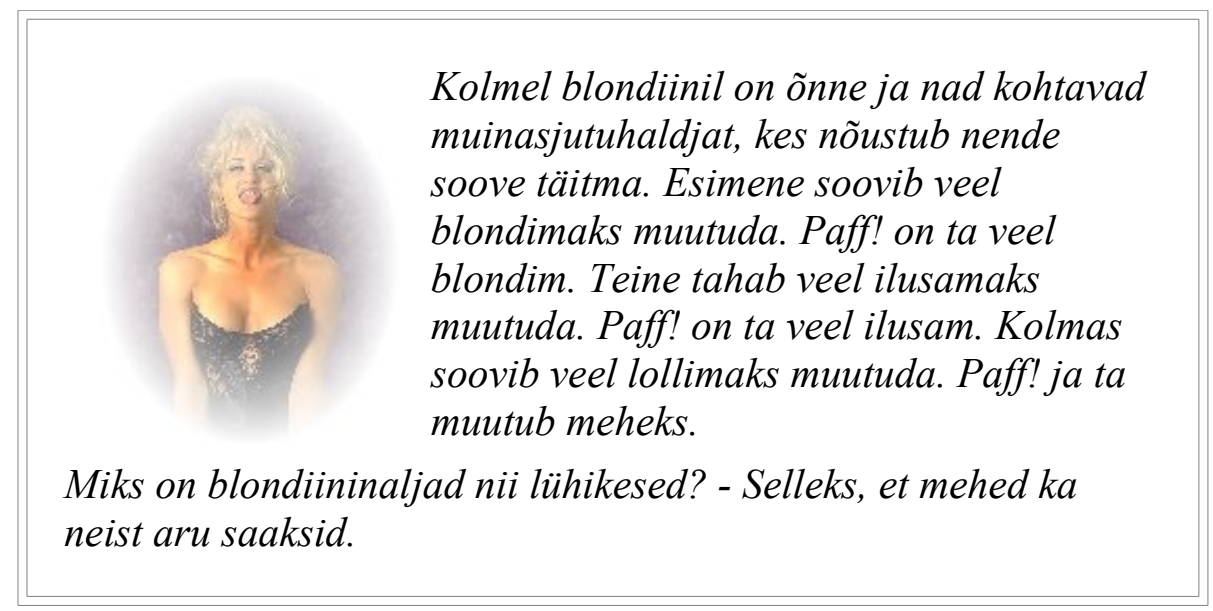

Nagu toodud näidetes, on suurimas uuemate naljade grupis juttu just meeste intellektuaalsest ebakompetentsusest, see tähendab: varem olid lollideks seksikad kiisukesed, kes ühekülgselt vaid seksile fikseeruvad, tänapäeval on samas rollis tugevama soo esindajad:

Mis see on - kuus jalga ja maksimaalselt kuuekümnene IQ? - Kolm meest vaatavad spordisaadet.

Mis võtab kauem aega, lumemehe või lumenaise ehitamine? - Lumemehe ehitamine, sest sellel tuleb pea veel seest õonsaks teha.

Miks ei tule meestel kunagi hullu lehma tõbe? - Sest neil on niigi ainult sigadused peas.

Mida ütleb mees, kes nabani vees seisab? - See käib mul üle mõistuse.

Mehelik-shovinistliku suhtumise vastu on suunatud vanemast ajast üle kandunud naljad nagu:

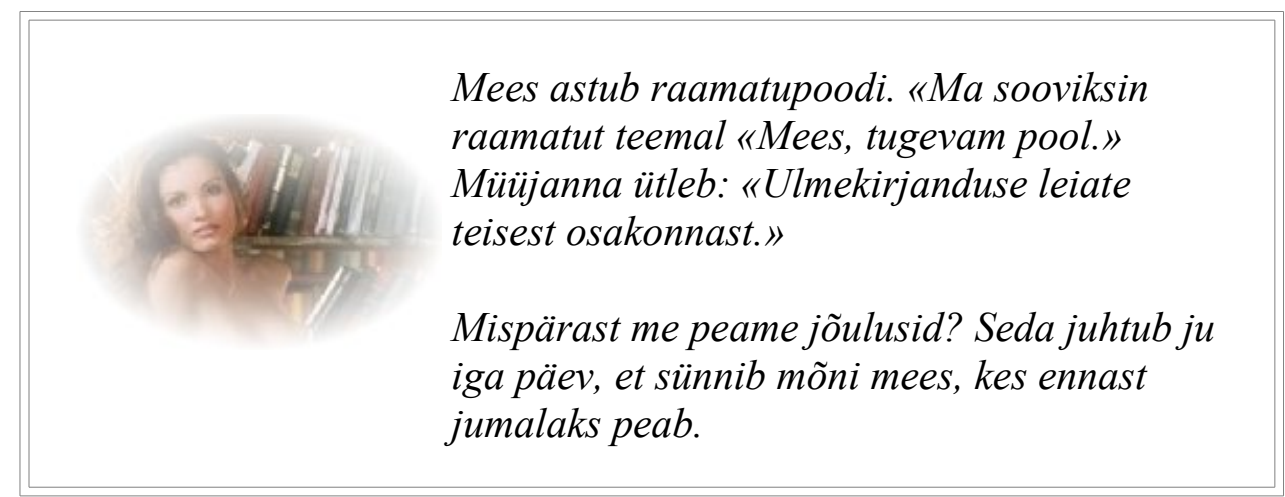


Ka erootika alal on mehed lollpead, kes kalduvad sealjuures reaalsustunustavasse eneseimetlusse:

Mis on vahet kliitori ja kõrtsi vahel? - Viimase leiavad mehed esimese ropsuga.

Viiskümmend protsenti meestest arvavad, et nende peenis on liiga väike, ülejäänud arvavad, et joonlauaga on midagi valesti.

Nagu misogüünses traditsioonis kasutavad nüüd ka naiste kurjad keeled aastasadu meeste pärusmaaks olnud loomavõrdlust:

Mida tähendab «Mees puuris»? - Liigile kohast pidamist.

Mõned naistenaljad jõuavad - nagu ülaltoodud meestenali arseeniga - meestest vägivaldsel teel vabanemiseni ning ootavad sellele teole ka pressi vastukaja:

Kui mees naise aknast välja viskab, millises ajalehes sellest siis kirjutatakse? - Bildis. - Aga kui naine mehe aknast välja viskab, millises ajalehes sellest kirjutatakse? - Ajalehes Schöner Wohnen (Kaunim elamine).

Mis see on - mees soolhappes? - Lahendatud probleem.

Paljude naiste arvates on meeste panus võrreldes naistega, kes lastekasvatuse ja töölkäimise topeltkoormuse ees siiski kohkuma ei löö, palju väiksem. Väikseimagi kodutöö juures on mehed kõlbmatud:

Mitu meest on vaja, et tühja WC-paberi rulli asemele unt panna?

- Seda ei tea keegi, sest seda pole kunagi juhtunud.

Samas liinis peaksid naislugejad mõistma ka järgmist «kuu parimat naistenalja» (pärit EMMAst nov/dets 1997): Miks pole meestel rindu? - Sest nad kukuksid lisakoormuse all kohe kokku. Iga kahe kuu järel ilmuv EMMA trükib igas numbris ühe meestevastase nalja, mida naised kindlasti märkavad ja edasi jutustavad. See teeb kokku kuus nalja aastas. Päritolu ja väljavaliku kriteeriumid ei ole teada. Enamus neist $E M M A$-naljadest baseerub paroodial, poolte vahetusel. 
Sarnane sugupoolte vahetamine oli märgatav postfeministlike teoreetikute juures (vrd Kimmunen 1996). Nii taipas näiteks Judith Butler, et vanu mõttemalle on kõige lihtsam hävitada parodeerimisega ning just see toimubki uuemas naistenaljas. Samas väljendab aga Butler ka arvamust: eelkäijate kogemused on põhimõtteliselt küll tervitatavad, aga ainult seni, kuni need ei soodusta sugudevahelise mõistmatuse süvenemist. Murelikud naisautorid hoiatavad, et uurimusi naistevaenulike naljade kohta ei peaks üldse avaldama, kuna oodatav tagasiside populariseeriks neid nalju veelgi (vrd Kotthoff 1996).

Seda dekonstruktivistlike postfeministide märguannet dihhotoomsete sooliste kategooriate asjus ei tohiks siiski valesti mõista. Mingil juhul ei tohiks see tekitada põhjendamatuid argumentatsioone, nagu sinisilmne teerajamine naiste allasurumisele, mis naistevaenulikus naljas väidetavalt niigi pigem marginaalina väljendub. Kasvav seksistlike naljade agressiivsus on fakt - et naised mehi nende endi relvadega ründavad, on õigustatud reaktsioon. Pahatahtlike naljade artikli lõpus, mille peale lugejad õieti sugugi naerma ei oleks pidanud, jäävad paljud küsimused endiselt lahtiseks. Ka järgnevad üldistused on esialgsed:

1. Uuematele naistenaljadele on tunnuslik vastulöök samade relvadega, eelkõige sama teravate relvadega. See vastulöögi-meetod ei näi vahendite kõrval, mida naised muudel aladel kasutavad, eriti originaalne, on aga väga sobilik meestenaljade strateegia paljastamisel. Selles seisnebki õieti ümberpööramise või kohavahetuse mõte. Et naljade toon selle juures pahatahtlike meestenaljade omaga sarnanema hakkab, pole naistevaenulikku eellugu teades mingi ime.

2. Naljade rääkimist on traditsiooniliselt peetud mittenaiselikuks. Aastasadu oli see meeste pärusmaa. Ülima tõenäosusega on naised osalt teadlikult selle traditsiooni lõhkunud ning aktiivseteks jutustajateks saanud. Seejuures jutustatakse ülaltoodud nalju eelkõige puhtalt naiste seltskonnas, vahel aga ka meeste läheduses, kasutades lõpuks aktiivselt isiklikku meediat. Ka seda rollide vahetamise vormi võib vaadelda teadliku uue strateegiana vanas sugudevahelises võitluses.

3. Mitte ainult traditsioonilistest naistevastastest naljadest, vaid ka nende mõnikord tõeliselt meestevaenulikest vastetest, nähtub endiselt hirm, võiks öelda numinoosne kartus vastassoo ees, millele kohandatakse jutustamise käigus lihtsamad ja kodusemad seletusmallid. Pahatahtlikkus, paha annab sellele «kogu hingega naljaga tegelemisele» arutluse ilme, mis tekitab konflikti lahendamisele meelega vastuseisu.

Tõlkinud Reet Hiiemäe ajakirjast Kuckuck, nr 11998.

\section{Vt ka tõlkija kommentaar}




\section{Kirjandus}

Bausinger, Hermann 1995. Standardisierte Spontaneität. Eine Skizze zum Erzählen von Witzen. Brunold-Bigler, Ursula \& Bausinger, Hermann (toim). Hören-Sagen-Lesen-Lernen. Bausteine zu einer Geschichte der kommunikativen Literatur. Bern, lk 13-22.

Freud, Sigmund 1989. Der Witz und seine Beziehung zum Unterbewußten. Frankfurt am Mainz. Humor. International Journal of Humor Research (1988 jj.). Berlin \& New York.

Huffzky, Karin 1979. Wer muß hier lachen? Das Frauenbild im Männerwitz. Eine Streitschrift. Darmstadt \& Neuwied.

Jolles, André 1958. Einfache Formen. Tübingen.

Kimmunen, Eeva Liisa 1996. Kvinnor i kulturventenskapling humorforskning. Palmenfeld, Ulf (toim) 1990 Humor och kultur. NIF-Publications 34. Turku, lk 103-115.

Kotthoff, Helga (toim) 1996. Das Gelächter der Geschlechter. Humor und Macht in Gesprächen von Frauen und Männern. UVK Soziologie. Konstanz.

Kutter, Uli 1978. Bemerkungen zur Jokelore. Zeitschrift für Volkskunde, nr 74, 1k 76-89.

Lixfeld, Hannjost 1978. Witz und Aggression. Zur Begriffsbestimmung und Funktion der Textsorte. Zeitschrift für Volkskunde, nr 74, lk 1-19.

Mieder, Wolfgang 1982. «Eine Frau ohne Mann ist wie ein Fisch ohne Velo!» Sprachspiegel, nr 38, lk 141-142.

Moser-Rath, Elfriede 1978. Frauenfeindliche Tendenzen im Witz. Zeitschrift für Volkskunde, nr 74, 1k 40-57.

Röhrich, Lutz 1990. Joke and Modern Society. Röhrich, Lutz

Wienker-Piepho, Sabine (toim). Storytelling in Contemporary Societies. ScriptOralia 22. Tübingen. Schenda, Rudolf 1978. Witze, die selten zum Lachen sind. Bemerkungen zur gegenwärtigen französischen Witzblatt-produktion. Zeitschrift für Volkskunde, nr 74, 1k 58-75.

Schenda, Rudolf 1993. Von Mund zu Ohr. Bausteine zu einer Kulturgeschichte volkstümlichen Erzählens in Europa. Göttingen.

Wehse, Rainer 1979. Männerfeindliche Tendenzen im Witz und Schwank? Diskussion. Zeitschrift für Volkskunde, $\mathrm{nr}$ 75, 1k 57-65.

\section{Kommentaarid}

*1 Ute Ehrhardti bestseller, esmakordselt ilmunud 1994, seejärel 1997. Tõlgitud viieteistkümnesse keelde. Samalt autorilt on vahepeal ilmunud «Käsiraamat nõuannetega raamatu ideede rakendamiseks igapäevaelus».

*2 See väljend toetub H. Arendti teesile «kurjuse banaalsuse» kohta ja pärineb Dieter Wyssilt: Kain - eine Phänomenologie und Psychopathologie des Bösen. Würzburg 1997.

*3 Üks vanimaid feministlikke uurimusi selle teema kohta on Carol A. Mitchelli The sexual perspectives in the appreciation and interpretation of jokes, mis ilmus ajakirjas Western Folklore, nr 36, 1977, lk 303-329.

*4 Selle artikli traditsioonilised, erilise markeeringuta naljad on pärit Freiburgi arhiivist, mis oli baasiks ka Röhrichi uurimusele. Uuemad naistenaljad pärinevad suurelt jaolt ajakirjast Emma, muude eest võlgnen tänu Rainer Wehse eraarhiivile (München) ja isiklikule kogumistööle, millega olen tegelenud neli aastat. Oma ülestähendused tegin naiste püsiseltskondades saunas, trammis, töö juures, kohvinurgas jne. Need on jutustamiskohad, kus minu kogemuse kohaselt kõige meelsamini jutustatakse / jutte levitatakse.

*5 See väljend tuleneb etteheitest «ala feminiseerumise» kohta. Uurimisseisu kohta jutu-uurimise 
vallas vt Sabine Wienker-Piepho: Genderlect. Plenaarettekanne, peetud 20. DGV kongressil Marburgis 1997. Kongressikogumikku toimetavad Martin Scharfe ja Christel Köhle-Hezinger.

*6 Ettekannete puhul Minskis oli väga huvitav jälgida, et blondiininaljadest ei saadud tihti aru, seevastu naersid tudengid ja naiskolleegid vägagi mõnede uute meeste kohta käivate naistenaljade üle.

*7 Vihje eest olen tänu võlgu B. Schubartile (München), kelle väitekirja teemaks on huumor kontekstis.

*8 Vrd Journal of American Folklore 1972. Selles on trükitud American Folklore Society 1970. aasta konverentsi teesid, mis oli pühendatud teemale Obstsöönsus suulises, ajaloolise levikuga jutuvormides.

*9 Vrd näiteks EMMA aastakäike 1995-1997. 